\title{
Experimental Analysis Of Tribological Properties Of Various Lubricating Oils Without And With Using Extreme Pressure Additives By Using Four Ball Extreme Pressure Oil Testing Machine
}

\author{
${ }^{1)}$ Prof.Dr. A. D. Dongare, ${ }^{2)}$ Prof. A. J. Gite \\ ASST.PROF. \& HOD in Mechanical Engineering Department; Shri Chhatrapati Shivaji College of Engineering, \\ Shrishivajinagar (Rahuri Factory) - 413706, Tal.-Rahuri, Dist.-Ahmednagar, \\ Mobile Number:-9270723202, \\ HOD in Mechanical Engineering Department; ( $2^{\text {nd }}$ Shift), Pd. Dr. V. V. P. I. Of Tech. \&Engg. (Polytechnic), \\ Loni-413736,
}

\begin{abstract}
This study examined the tribological properties of various lubricating oils (i.e.SAE20, SAE30, SAE40, SAE68, SAE90, SAE120, \& SAE140) which are used for various purposes like lubrication of Bearings, I.C.Engine Parts, Machine Parts, Cutting oils in manufacturing processes and specially Gear boxes lubrication oils etc., without and with using different antiwear \& extreme pressure additives (i.e. MOLYVAN A \& VANLUBE 73). By using Four Ball Extreme Pressure Oil Testing Machine (F.B.E.P.O.T.M) which plays an important role in oil industry while selecting such oils as a lubricating media for testing various types of E.P. lubricating oils. The test was carried out as per the American Society for Testing of Materials (ASTM) ASTMD2783-3 [The Standard Test Method for Measurement of Extreme-Pressure (EP) Properties or an evaluation of tribological properties of lubricating oils by Four-Ball Method] \& IP-239 [Determination of Extreme Pressure and Anti-wear Properties of Lubricants - Four Ball Machine Method] to determine the weld load.
\end{abstract}

The Extreme Pressure (E.P.) Properties like- (1) Load Wear Index (LWI) (i.e. Mean Hertz Load); (2) Weld Point (WP); (3) Last Non-Seizure Load (LNSL) -Non load are the basis of differentiation of lubricating fluids having low, medium and high level of E.P. Properties. Load Carrying Capacity of EP lubricating oil is important parameter for their application. The viscosity shows anti wear benefits to lubricants noticed through decrease in wear scar diameter with increasing viscosity by varying percentage of additives. The anti wear additive studied have been found to show anti wear properties of lubricants under the experimental condition. The test was carried out on four ball testing model under atmospheric pressure of lubricant at different loads and at room temperature. Anti wear properties of oils like 90 EP and 140 EP gear oil are evaluated Critical Seizure Load, Weld Load, and Wear Index are determined.

Additives are substances formulated for improvement of the anti-friction, chemical and physical properties of base oils (mineral, synthetic, vegetable or animal), which results in enhancing the lubricant performance and extending the equipment life. Combination of different additives and their quantities are determined by the lubricant type (Engine oils, Gear oils, Hydraulic oils, cutting fluids, Way lubricants, compressor oils etc.) and the specific operating conditions (temperature, loads, machine parts materials, environment). Amount of additives may reach $30 \%$. Wear is the progressive loss of material from the operating surface of machine due to relative motion between surfaces. Wear occurs in mating parts in a given environment under certain operating condition like Load, Speed, and Sliding Distance Etc. Lubricating oil plays an important role in manufacturing industry because lubricant is used to reduce frictional losses and avoid metal-to-metal contact between the components assembled together for obtaining desired function in machine.

Wear properties of materials and Extreme pressure properties of lubricants are presently determined by various equipment like four ball wear extreme pressure tester, pin on disc tester, grease noise tester, scratch tester, etc. Reduction of wear and coefficient of friction between two sliding surfaces under practical condition is paramount important for Design Engineer, The four ball-testing machine is proposed to find wear preventive properties of various lubricants.

The

test was carried out as per the American Society for Testing of Materials (ASTM) ASTM-D2783-3 [The Standard Test Method for Measurement of Extreme-Pressure (EP) Properties or an evaluation of tribological properties of lubricating oils by Four-Ball Method] \& IP-239 [Determination of Extreme Pressure and Antiwear Properties of Lubricants - Four Ball Machine Method] to determine the weld load. The Extreme Pressure (E.P.) Properties like- (1) Load Wear Index (LWI) (i.e. Mean Hertz Load); (2) Weld Point (WP); (3) Last NonSeizure Load (LNSL) -Non load are the basis of differentiation of lubricating fluids having low, medium and high level of E.P. Properties.

In this paper 
we have evaluated and investigated of tribological properties (i.e. Load Carrying Capacity or Extreme Pressure properties or Weld Points etc.) of various lubricating oils without using Extreme pressure Additives. And the wear preventive properties of various lubricants are found by using Four Ball Oil Testing Machine. The test is carried out on alloy steel balls for two hours under three varying loads. The following types of test are carried out on four market available lubricants.

\section{INTRODUCTION}

The concept of Tribology was enunciated in 1966 in a report of the UK Department of Education and Science. It encompasses the interdisciplinary science and technology of interacting surfaces in relative motion and associated subjects and practices. It includes parts of physics, chemistry, solid mechanics, heat transfer, materials science, lubricant rheology, reliability and performance. Although the name tribology is new, the constituent parts of tribology encompassing friction and wear are as old as history. The economic aspects of tribology are significant. Investigations by a number of countries arrived at figures of savings of $1.0 \%$ to $1.4 \%$ of the GNPs, obtainable by the application of tribological principles, often for proportionally minimal expenditure in Research and Development. Lubrication, is a constituent of Tribology (Tribology is the Science \& Technology of the interactions between surfaces moving relative to each other), is one of the powerful means of reducing frictional resistance of surface having relative motion under load. It includes hydrodynamic, hydrostatic and Elasto Hydrodynamic Lubrication (EHL) utilizing either oils or liquids or gasses as lubricants.

It has been established since long that those surfaces of the bodies are never perfectly smooth. It is due to these corrugations that friction arises. However smooth the surfaces may be seen, friction still exists between them. Lubrication, is a constituent of Tribology (Tribology is the Science \& Technology of the interactions between surfaces moving relative to each other), is one of the powerful means of reducing frictional resistance of surface having relative motion under load. It includes hydrodynamic, hydrostatic and Elasto Hydrodynamic Lubrication (EHL) utilizing either oils or liquids or gasses as lubricants. The lubricating oils are selected considering the various operations condition like temperature rise, working load, normal working temperature; Pressure, Extreme conditions etc. lubricating oils are categorized by either composition or end use. They are divided in two groups -mineral oils and vegetable or animal oils, but consumers prefer terminology that reflects the use of the lubricant. The terms or names given below have been selected on the basis of their common acceptance and usage. (1) Extreme Pressure (EP) oils, (2) Compound oils, (3) Detergent oils (4) Synthetic oils (Fluids). Due to the accuracy of results and Due to the simple test procedure of this F.B.E.P.O.T.M. is widely used in oil industries as well as in Research and Development (R \& D) Institutes.

The F.B.E.P.O.T.M. is utilized for finding out the load carrying capacity and weld point of different types of lubricating oils without E.P. Additives; $\quad$ The various Advantages of this (F.B.E.P.O.T.M.) machine are

1. The construction is quite easy to understand.

2. The balls used in this testing machine are easily available and of low cost.

3. The range of temperature for testing Oil is quite large $180 \mathrm{C}$ to $350 \mathrm{C}$.

4. Large variety of oils is tested by this Machine.

5. As measurement of scar on the balls under microscope is very easy so by comparing from table we can easily predict the load carrying capacity of given oil.

The parameters were determined as Wear-Scar Diameter (WSD), Initial Seizure Load (ISL), Just Before Weld Load (JBWL) And Weld Load (WL) etc.

Extreme pressure and anti wear additives prevent metal to metal contact by adding film forming compounds that protect the surface either by physical absorption or a chemical reaction with the metal surface in order to form a low shear film at point of contact. The principal function of lubricants are to control friction, Wear, temperature, corrosion, Insulate (Electric), Transmit power (Hydraulic), Dampen shock (Viz-dashpots, gears), Remove contaminants (Flushing action) and form a seal (grease).

The addition of extreme pressure (EP) and anti wear (AW) additives was used to improve the friction and wear behaviors of lubricant, thus, avoiding surface damage. In the boundary lubrication regime, the formation of a surface chemical reaction film is the determining factor in minimizing the friction and wear.

Various Researchers or Tribologiest or Scientists or Companies developed EP Testing Machines (F.B.E.P.O.T.M.) and Carried out an Evaluation of tribological properties of various lubricating oils-specially Gear Boxes oils by using Various Four Ball Extreme Pressure Oil Testing Machines (F.B.E.P.O.T.M.).

Lubricants are used to prevent wear between moving parts and to resist to high pressure between them. There are standardized testing methods that determinate the wear of the contact pair pieces and the pressure that leads to lubrication failure. The standards present the conditions and procedure of the test and the equipment. This failure manifests at the beginning through a seizure and at the end through a welding between metallic 
separated parts. All these methods are used the four ball machine because of its constructive simplicity and easy utilization, in spite of its obsolete and given little correlation to the lubricant behaviour in real applications from the point of view of some researchers. In this paper the authors compare three such standards related to the use of four-ball machine, two American (ASTM D 2783, ASTM D 4172) and the Romanian one (SR EN ISO 20623:2004), this being adopted by the endorsement method of the standard EN ISO 20623:2003.

The addition of extreme pressure (EP) and anti wear (AW) additives was used to improve the friction and wear behaviors of lubricant, thus, avoiding surface damage. In the boundary lubrication regime, the formation of a surface chemical reaction film is the determining factor in minimizing the friction and wear. This depends on the nature and chemistry of additives or tribological effects of their active elements (sulphur, phosphorus, nitrogen, chlorine, etc). Metallic dialkyldithiocarbamates of zinc, lead, molybdenum, etc have been widely utilized as a multifunctional lubricant additive to provide antiwear protection as well as to inhibit the oxidation of petroleum lubricants. The effect of a particular additive depends on its chemical nature, and its concentration. However, they don't exhibit better antiwear and extreme pressure properties under different operational conditions. The wide variety of positive effects demonstrated by the combination of different types of additives. The required functional action is achieved by appropriate balance. Investigations that can optimize the composition and expand the areas of application of additive packages are of considerable scientific and practical interest.

The hardness of mating surfaces is an important component of the so-called friction parameters vector and has a significant influence on the magnitude of the friction and on the wear of the surfaces. Investigations aimed at determining the influence of hardness on the wear of machine parts working in mixed lubrication range were carried out using a four-ball extreme pressure tester. The test balls were made of $100 \mathrm{Cr} 6$ steel with a hardness of 24-62 HRC. A mixed lubrication model (an objective function) correlating the hardness of the steel sliding surfaces the magnitude of the friction and the wear of the surfaces in a defined area of excitations (pressure $p \mathrm{H}$ and sliding velocity $v$ ) for lubrication with oil Transol 150 has been developed. Hardness has been found to have a significant influence on wear. Thanks to the correlation of hardness with the excitations it has been observed that the objective function $d=f(p \mathrm{H}, v, H)$ is not a monotone function, but it has an extremum. The model allows one to match steel materials for sliding nodes working under concentrated contact (e.g. in gears) without the need to carry out experimental tests.

\section{CONSTRUCTION FEATURES}

As concerning the laboratory tests for lubricants, an important role among these is played by the determination of anti-wear and extreme pressure properties. In the first test the lubricant plays its protection role but in the second one it fails due special experimental conditions. The equipment that could do these tests may be grouped into two main categories (a) laboratory equipment that models the tribological processes characterizing the actual industrial tribosystems or they try to generate a friction process under well-determined conditions; many of these tests are used particularly for obtaining comparative data; (b) laboratory equipment using tribosystems included in different actual technical systems, monitored by adequate measuring devices.

The EP oils contain EP additives for lubricating gears and bearings under high loads. High impact loads from shocks and high rolling pressure may cause oil films between moving parts to rupture, resulting in metal to metal contact and rapid wear. To prevent such damage, EP oils are formulated with additive compounds that interpose an appropriate chemical under load, the chemical attaches itself to reacts with the metal surface at the elevated temperature forming an intervening compound to reduce friction and prevent wear

\section{Standard Test Method For Measurement Of Extreme Properties Of Lubricating Fluids By Four Ball Method Astm D-2783}

The Test Method is used to determine the Load Carrying Capabilities of Lubricating Fluids; Test Method is used for Specification Purposes in Order to Differentiate between Lubricating Fluids Having Low, Medium, and High Levels of Extreme Pressure in Sliding Steel-On-Steel Conditions. Two Determinations are made in This Test. The Load Wear Index and the Weld Point. The Load Wear Index is an Index of the Ability of a Lubricant to Prevent Wear at Applied Loads. The Weld Point is the Lowest Applied Load at Which the Sliding Surfaces of Four Steel Balls Seize and Weld Together.

In This Test Steel Balls of the Same Size and Metallurgy are used. Three Steel Balls which are immersed in the Lubricant Being Tested are locked into a Test Cup. A Fourth Steel Ball that is Held in Place in a Rotating Chuck is placed on Top of the Three Steel Balls Locked in the Test Cup. The Fourth Steel Ball is rotated at a Speed of 1770rpm and Subjected to a Series of 10 second durations at Increasing Loads until Welding of the Steel Balls Occurs. At the End of each 10 Second Test, the Ball in the Chuck is discarded and the Other Three Balls are taken from the Cup in Order to Examine the Diameter of the Wear Scar. These Wear Scar Diameters are used to calculate the Load Wear index. With Each Load Applied New Steel Balls are used. 
The Loads are applied in a Stepped Series with the First Load Being 6kgsf. The Loading Series Used is $6,8,10,13,16,20,24,32,40,50,63,80,100,126,160,200,250,315,400,500,620$ and $800 \mathrm{kgsf}$. If Welding Does not Occur at $800 \mathrm{kgsf}$ the Lubricant is reported as Having a Weld Point of $+800 \mathrm{kgsf}$.

\section{FOUR-BALL WEAR AND EP TEST}

This tester was developed to evaluate the antiwear, EP, and antiweld properties of lubricants. It is a simple bench test machine designed to measure the protection a lubricant provides under conditions of high unit pressures and various sliding velocities. The Four-Ball Wear tester consists of four 1.5 in. diameter steel balls arranged in the form of an equilateral tetrahedron. The three lower balls are held immovably in a clamping pot, while the fourth ball is made to rotate against them. Test lubricant is added in the test pot, covering the contact area of the test balls. During a test, wear scars are formed on the surfaces of the three stationary balls. The diameter of the scars depends on the load, speed, temperature, duration of run, and type of lubricant. The FourBall EP tester runs at a fixed speed of $1770 \pm 60 \mathrm{rpm}$ and has no provision for lubricant temperature control.

A microscope is used to measure the wear scars. Two of the standard tests run on the Four-Ball machine are Mean-Hertz Load and Load-Wear Index. ASTM D 2596 covers the detailed calculation procedure of Load-Wear Index for greases and D-2783 for oils. These procedures involve the running of a series of $10 \mathrm{~s}$ tests over a range of increasing loads until welding occurs. From the scar measurements, the mean load (load wear index) is calculated and it serves as an indicator of the load-carrying properties of the oil being tested.

\section{TEST PROCEDURE OF FOUR BALL E.P. TEST}

The determination of the load carrying capacity of a lubricant in kilogram applied to a system of four steel / Cast iron balls in the form of a tetrahedron (See Fig.1. Four Ball Extreme Pressure Oil Testing MachineBelow). As per ASTM D2783, Four Ball EP test steel / Cast iron balls of the same size and metallurgy are used (Cr.Alloy steel or Cast iron material for balls of Dia. $12.7 \mathrm{~mm}$ ), Three steel /cast iron balls which are immersed in the industrial gear lubricating oil being tested, are locked in to a test cup . A fourth steel ball that is held in place in a rotating chuck is place on top of the three steel Cast iron balls locked in the test cup. The fourth steel ball is rotated at a speed of $1770 \mathrm{rpm}$ and subjected to a series of 10 second duration's at increasing loads until welding of the steel/cast iron balls occurs. At the end of each 10 second test, the ball in the chuck is discarded and the other three balls are taken from the cup to examine the diameter of the wear scar under standard magnifying Microscope, These wear car diameter to calculate the load wear index. New steel/Cast iron balls are used with each load applied.

A series of 10-second runs are made at pre-selected loads shown in the first column of the four ball EP worksheet. The first run is made with a load of $40 \mathrm{~kg}$ (Marked base) and subsequent runs at successively higher loads until welding of the four balls occurs. Two check runs at the welding load are made, and if welding does not occur in both of the check runs, the next higher load is applied until welding occurs. The three lower balls are retained in a holder for measurement of the scar diameters. The work sheet data collected from the determination of the load scar curve are used in calculations under the Mean Hertz load formula for the determination of the E.P value.

\section{SCAR DIAMETER MEASUREMENT}

Two measurements are made of the wear spots on each of the three lower balls. One measurement is made horizontally and the second measurement is made vertically. These measurements are recorded in columns one through six on the shell four ball EP worksheet. The arithmetic mean of the six measurements is obtained and placed in column X. The average scar diameter readings are plotted against $\mathrm{kg}$. Load as part of the report.

$$
\text { Corrected Load }=\stackrel{\text { LDH }}{-------}
$$

(Where, L=Load, DH= Hertz Diameter, $\mathrm{X}=$ Average Scar Diameter.)

Total corrected Loads

Extreme Pressure value $=$

Number (15 min.) of progressive runs

\section{WELD POINT}

Weld point is that point at which there is immediate seizure of the four balls and is the end point of the test. This point is shown on the load scar curve by a vertical arrow at the loading above the last measurable scar recorded.

EP VALUE

The Hertz line diameter is calculated from the formula determining the diameter of the contact area between two spherical surfaces. This diameter is the static indentation caused by deformation of the balls under 
load at the start of the test. This dimension is shown on the four ball worksheet as factor DH, where LDH is used to determine the corrected load.

\section{TEST RESULTS}

The objectives of this procedure are completed with the plotting of the load scar curve including weld point and calculations of the EP value.

Minimum Scar Diameter (MSD) =

Horizontal (Parallel) Reading (HR) + Vertical (Normal) Reading (VR)

M.S.D. =

2

Average Reading

M.S.D. $=\frac{}{2}$ in $\mathrm{mm}$.

Typical Test Results Of Gear Oils Obtained With The F.B.E.P.O.T.M. Are Shown In The Following

Table No. 1

TABLE 1. TEST RESULTS - F.B.E. P.O.T.M.

\begin{tabular}{|c|c|c|c|}
\hline $\begin{array}{c}\text { SR. } \\
\text { NO. }\end{array}$ & LUBRICANTS & $\begin{array}{c}\mathbf{2} \mathbf{1} \mathbf{2} \text { INCH, } \\
\text { SD, KG }\end{array}$ & $\begin{array}{c}\text { MEAN HERTZ LOAD } \\
\text { KG }\end{array}$ \\
\hline 1 & Mineral Oil & 73 & 26 \\
\hline 2 & Castor Oil & 88.5 & 30 \\
\hline 3 & Pb Soap - S gear Oil & 106 & $>86$ \\
\hline 4 & $6 \%$ fatty oil & 69.5 & 24 \\
\hline 5 & $5 \%$ Commercial EP additive & 131 & 65 \\
\hline 6 & $15 \%$ commercial EP additive & 149 & 84.5 \\
\hline 7 & Commercial gear oil SAE 90 & 87.5 & 46 \\
\hline
\end{tabular}

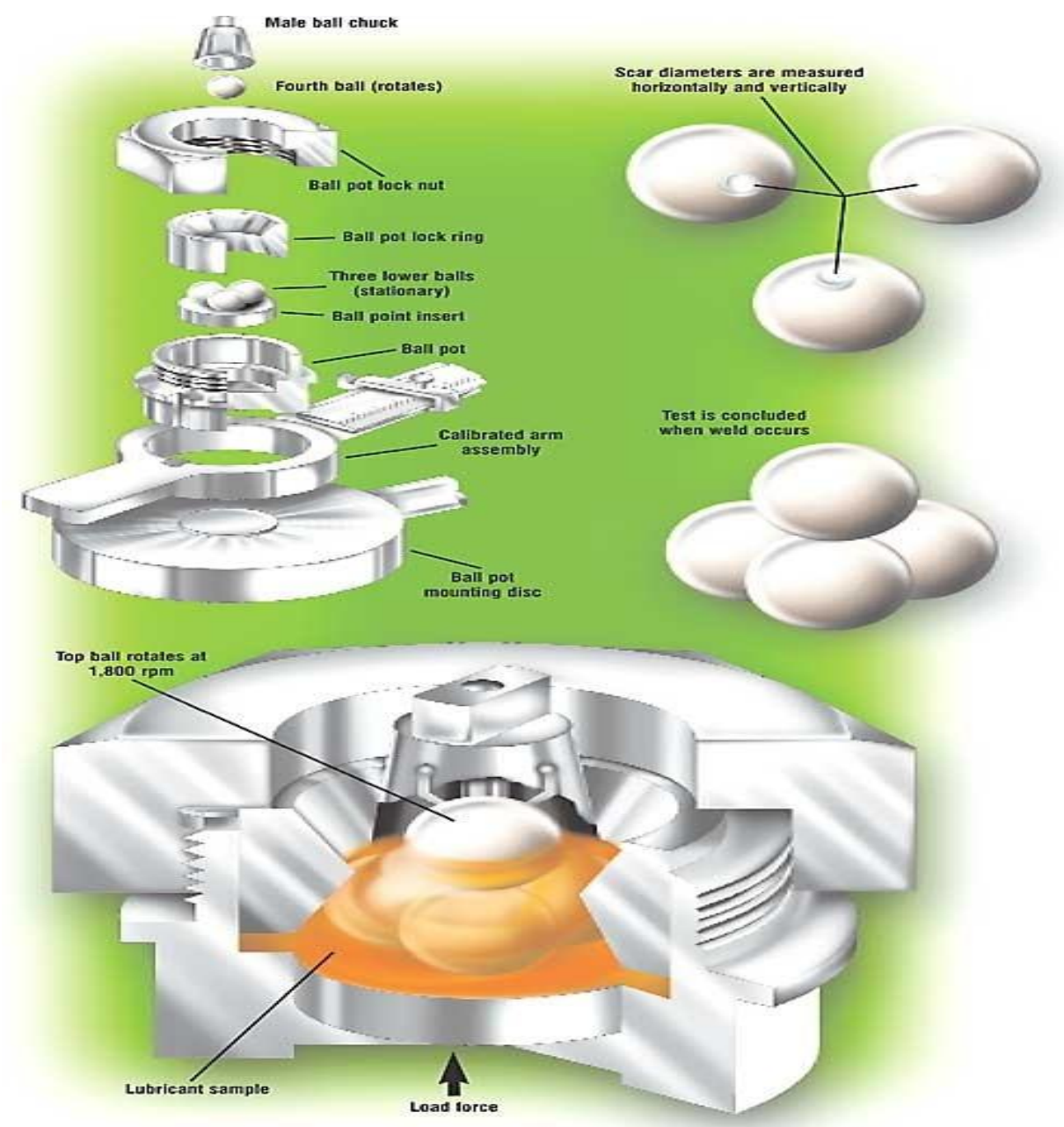

FIG.1. FOUR BALL EXTREME PRESSURE OIL TESTING MACHINE 


\section{ANTIWEAR \& EXTREME PRESSURE ADDITIVES DITHIOCARBAMATES MOLYVANA}

Used in long life chassis greases for ball joints, steering linkages and other lubricating greases requiring good antioxidant and antiwear at high temperatures for long periods of time. MOLYVAN A is an organic molybdenum E.P. and antiwear additive for petroleum and synthetic lubricants. It has good high temperature stability. In lubricating greases it is superior to inorganic molybdenum additives in both antiwear and antioxidant properties.

MOLYVAN A is slightly basic and does not promote rusting. It has a low specific gravity which makes it easy to disperse with simple equipment. It is used in non-petroleum base valve lubricants. (Application-Grease, Synthetic Lube, Function-High Temperature, Antioxidant, Antiwear/Antiscuff, Friction Reducer, Extreme Pressure, Chemical Composition-Molybdenum di-n-butyldithio- carbamate, Physical State-Powder, Color

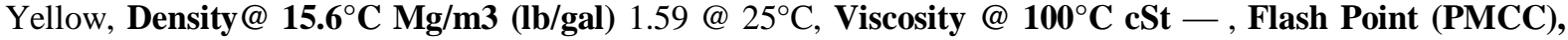
${ }^{\circ} \mathbf{C}$ - Solubility Slightly soluble in aromatic hydrocarbons. Insoluble in water, Use Concentration, \% mass 0.5 - 3.0, Typical Uses-MOLYVAN A is used in long life chassis greases for ball joints, steering linkages and other lubricating greases requiring good antioxidant and antiwear at high temperatures for long periods of time. It is an organic molybdenum extreme pressure and antiwear additive for petroleum and synthetic lubricants. It has good high temperature stability. In lubricating greases it is superior to inorganic molybdenum additives for both antiwear and antioxidant properties. MOLYVAN A is slightly basic and does not promote rusting. It has a low specific gravity which makes it easy to disperse with simple equipment. It is used in non-petroleum base valvelubricants.)

\section{MOLYVAN807}

MOLYVAN 807 offers a unique molybdenum-sulfur combination in an oil-soluble form which is easy to blend into lubricants. MOLYVAN 807 can be used to maintain the antifriction properties of an engine oil while reducing the phosphorus content. To obtain significant increases in extreme pressure properties and impart improved antiwear performance, MOLYVAN 807 can be used in combination with VANLUBE ${ }^{\circledR} 7723$, a nonmetallic dithiocarbamate which functions as antioxidant and extreme pressure agent. Note: Since oil formulations vary it is recommended that upon the incorporation of any additive the finished product be tested to confirm original test results. In some formulations, the presence of MOLYVAN 807 may contribute to copper corrosion which would be detrimental to some diesel engines. Therefore, its use in such lubricants is not recommended.

\section{MOLYVAN 822}

MOLYVAN 822 may be used to maintain or improve the antifriction properties of an engine oil while reducing the phosphorus content. MOLYVAN 822 is less corrosive to copper than most other organic molybdenum compounds. MOLYVAN 822 is not recommended for use in diesel engine lubricants. Note: Since oil formulations vary it is recommended that upon the incorporation of any additive the finished product be tested to confirm original test results. In some formulations, the presence of MOLYVAN 822 may contribute to copper corrosion which would be detrimental to some diesel engines. Therefore, its use in such lubricants is not recommended.

\section{VANLUBE EZ}

VANLUBE EZ is a multifunctional additive that imparts excellent antiwear, extreme pressure, corrosion resistance, and antioxidant properties to industrial lubricants and greases. It is a concentrated version of VANLUBE AZ. The product is a clear, light-colored, and free-flowing liquid.

\section{VANLUBE 73}

One of the most versatile of the dithiocarbamate additives. VANLUBE 73 has excellent anti-wear, extreme pressure and antioxidant properties. It is used as an antiwear additive, bearing corrosion inhibitor in motor oils, gas engine oils, compressor oils, etc. It is used in lubricating greases of all types as an antioxidant, antiwear and extreme pressure additive. (Application-Compressor Oil, Engine Oil, Gear Oil, Grease, Synthetic Lube, Function- Antioxidant, Antiwear/ Antiscuff, Friction Reducer, Extreme Pressure, Chemical Composition-Antimony tris (dialkyl dithio carbamate) in oil, Physical State- Clear to Hazy Liquid, ColorDark Amber, Density @ 15.6 ${ }^{\circ} \mathbf{C ~ M g / m 3 ~ ( l b / g a l ) - ~} 1.03$ (8.6), Viscosity @ 100 ${ }^{\circ} \mathbf{C}$ cSt - 11, Flash Point (PMCC), ${ }^{\circ}$ C- 171, Solubility- Soluble in petroleum and synthetic lubricant bases. Insoluble in water, Use Concentration \% mass $-0.1-1.0$ as antioxidant 2.0 - 5.0 as extreme pressure agent, Typical Uses-VANLUBE 73 is one of the most versatile of the dithiocarbamate additives. It has excellent antiwear, extreme pressure and antioxidant properties. It is used as an antiwear additive, a bearing corrosion inhibitor in motor oils, gas engine oil, compressor oils, etc. It is used in lubricating greases of all types as an antioxidant, antiwear and extreme pressure additive.) VANLUBE 73 SUPER PLUS 
VANLUBE 73 Super Plus is a proprietary mixture of dialkyldithiocarbamates. Based on equivalent antimony content the load-carrying capacity of VANLUBE 73 Super Plus is superior to that of antimony dialkyldithiocarbamate (SDDC), and comparable to that of combinations of SDDC and sulfurized olefin. As an antioxidant, VANLUBE 73 Super Plus outperforms both SDDC and SDDC/sulfurized olefin and, unlike sulfurized olefin, it does not lower the dropping point of lithium complex grease. VANLUBE 73 Super Plus does not have a pungent odor of sulfurized olefin.

\section{VANLUBE 869}

VANLUBE 869 is an effective EP/antioxidant suitable for lubricating oils and greases. VANLUBE 869 is compatible with other VANLUBE RI's/AO's and metal deactivators.

\section{VANLUBE 8610}

VANLUBE 8610 is an EP/antioxidant useful for various lubricating oils and greases. Impressive Timken loads of 90 and $100 \mathrm{lbs}$. may be seen with $2 \%$ treatment levels. VANLUBE 8610 is compatible with other VANLUBE RI's/AO's and metal deactivators.

\section{VANLUBE 9413}

This product is a bismuth containing liquid extreme pressure additive. Laboratory tests show that $3.5 \%$ mass treatment in Lithium Complex greases yields an $80 \mathrm{lb}$. Timken OK Load. This product can also be used in fluid lubricants.

\section{EXPERIMENTAL SETUP (TEST RIG - F.B.E.P.O.T.M.)}

The F.B.E.P.O.T.M. is a standard rig test for an Evaluation of Extreme Pressure (E.P.) property of a Lubricating oils, in this machine (See Fig.2). The components of mechanical design of the testing area of Four Ball Extreme Pressure Oil Testing Machine, A Vertical spindle rotates a chuck between a speeds of $1200 \mathrm{rpm}$ to $1800 \mathrm{rpm}$, in which steel/cast iron ball of $12.7 \mathrm{~mm}$ diameter. With (i) EN 31- C-0.9 to $1.2 \%$, Mn.- 0.3 to $0.7 \%$, Cr-1 to $1.6 \%, \mathrm{Ni}-\mathrm{Nil} \%$ OR (ii) Alloy Steel - C-0.53\%, Mn-0.58\%, Cr- $0.48 \%, \mathrm{Si}-0.05 \%, \mathrm{P}-0.027 \%$ and FeBalance and VHN hardness of 670 (Average) were used test specimen is fitted below it three identical balls are clamped together tightly in a cup filled with lubricating oil $(5 \mathrm{ml})$ to be tested. The cup is mounted on a thrust bearing which automatically centres the top ball held in the chuck. Thus, the load is evenly distributed over three points of contact between the top rotating ball and the underlying three stationery balls. The loads are in the range of $20 \mathrm{~kg}$ to $40 \mathrm{~kg}$. (OR $549 \mathrm{~N}$ to $3479 \mathrm{~N}$ ) are applied on the thrust bearing by suspending lever arm with the temperature control within range of $18^{\circ} \mathrm{C}$ to $35^{\circ} \mathrm{C}$. The rotation of the driving spindle causes a friction torque, which is recorded on a rotating drum. The duration of the test is 60 Seconds.

\section{FOUR BALLS TEST}

The Four Ball Test (Machine) is used to measure the Anti Wear (AW) and Extreme Pressure (EP) properties of greases and lubricating oils. The point contact interface is obtained by rotating a $12.7 \mathrm{~mm}$ diameter steel ball under load against three stationary steel balls immersed in the lubricant. The speed of rotation, normal load, and temperature can be adjusted in accordance with published ASTM standards. To evaluate the anti wear characteristics of lubricants, the subsequent wear scar diameters on the balls is measured. To evaluate the Extreme-Pressure (load-carrying) capacity of lubricants, the normal load at which welding occurs at the contact interface is measured. (See Figs.2, 3, 4, 5,6)

\section{EXTREME-PRESSURE (EP) PROPERTY MEASUREMENTS (4-BALL EP TEST ASTM D-2783)}

The 4-Ball Extreme-Pressure Test evaluates extreme-pressure properties and high-load, anti-wear protection properties. High reported values indicate the gear lube Provides better protection against wear and galling when the lubricant film is ruptured under heavy loads. Towing, hauling, racing and highhorsepower/torque applications are examples of severe service where the lubricant film is commonly ruptured and metal-to-metal contact occurs. The 4-Ball EP Test is operated with one steel ball under load rotating at 1760 $\mathrm{rpm}$ against three steel balls submerged in oil and held stationary in a cradle. The temperature of the gear lube is brought to 18.33 to $35.0^{\circ} \mathrm{C}\left(65\right.$ to $\left.95^{\circ} \mathrm{F}\right)$. Weld point and load-wear index are determined from a series of 4-Ball EP Test runs.

A series of tests with increasing loads, measured in kilograms $(\mathrm{kg})$ are performed until the fourth loaded ball seizes (welds) to the three stationary balls. The weld point is the lowest (first) extreme-pressure point which exceeds the lubricant's load carrying ability. It is a good indicator of a lubricant's extreme-pressure properties. Gear lubes with weld points of $400 \mathrm{~kg}$ indicate better EP properties than those with weld points of $315 \mathrm{~kg}$. 


\section{EXPERIMENTAL PROCEDURE}

The experimental procedure follows the next steps: The balls were putted into the balls cap, and the cup was filled with oil as the standard EN ISO 20623:2004 requires; The oil was tested 30 minutes and then was removed from the ball cup; The balls were left in the ball cup and were washed up with proper solvent and then dried; The mean scar Diameters were determinate as the standard requires; A new fresh oil was introduced into the ball cup and tested for the next 30 minutes; Afterwards the above steps were repeated. Altogether the oil was tested six times for 30 minutes, i.e. three hours. To an evaluate the EP activity of the additives a number of test were performed until the welding point was reached. The wear scars were optically measured and the other parameters were calculated by the standard method.

IX.

THE EXPERIMENTAL TEST PROCEDURE

1. Thoroughly clean the new four test balls, test lubricant cup and holder assembly by first washing with acetone.

2. Place the three test balls in the test lubricant cup; place the lock ring over the test ball and screw down nut securely. Pour the lubricating fluid to be tested over the three tests Balls until they are covered.

3. Bring the lubricant and cup to $18^{0} \mathrm{C}$ to $35^{\circ} \mathrm{C}$.

4. Place the fourth ball into the ball chuck and fit to the vertical shaft.

5. Bring the test lubricant cup assembly on the test apparatus on contact with the fourth ball.

6. Install the test lubricant cup assembly on the test apparatus on contact with the fourth ball.

7. Apply the load with the help of hydraulic jack, making certain that cup assembly and Spacers are centered.

8. Start the motor and run for $10 \pm 0.2$ seconds.

9. Remove the test lubricant cup assembly, remove the chuck and discard the balls.

10. Measure the scar diameter of test balls as follows-

Remove the test balls, and clean the balls in Acetone. Wipe dry with soft cloth,

Using a microscope, measure to the nearest scar diameter both Parallel (Horizontal) and Normal (Vertical) to the striations in the scar surface of one of the three test balls.

11. Record for the $80 \mathrm{~kg}$ load, the average scar diameter by above method, Compare this Average scar diameter with the compensation scar diameter.

12. Make additional runs at consecutively higher test loads, recording measured scar Diameter and discarding test balls until welding occurs. Make a check run at this point of welding does not occur on the check run, repeat the test at the next higher load until Welding is verified.

14. If the measured scar diameter for $80 \mathrm{~kg}$ is more than 5\% from compensation scar Diameter (As shown in the above table 5.1.), Make the next run at the next lower load. Continue this procedure until the last non seizure load is determined.

14. Alternatively, in instances when the measure wear scars, remain more than 5\% above the compensation line, continue this procedure until a total of 10 runs below the weld Point is recorded.

\section{PRECAUTIONS}

Following Precautions should be taken while carrying the test.

1. Do not allow the contamination of lubricant with foreign materials and other lubricant

2. Do not use solvents such as carbon tetrachloride or other solvent that may inherently Posses load carrying properties.

3. The force on the lock nut is maintained within the range $68 \pm 7 \mathrm{Nm}$, measured by torque Wrench.

4. Cup assembly, Spacer and load point should be centered.

5. Scar diameter and volume loss should be measured precisely in PREC laboratory.

6. Time for each test should be measured correctly and pressure should be maintained within the range.

7. During the higher loads and weld load, it is difficult to measure scar diameter, due to Flow of metal, in such cases the metal flow can be removed or peeled or with a suitable instrument.

8. Shut off the motor immediately to prevent damage to the tester.

Welding may be detected (i) Increased noise level of motor, (ii) Smoking from test oil cup, (iii) Sudden drop in pressure.

9. Ensure zero of pressure indicator before loading. 


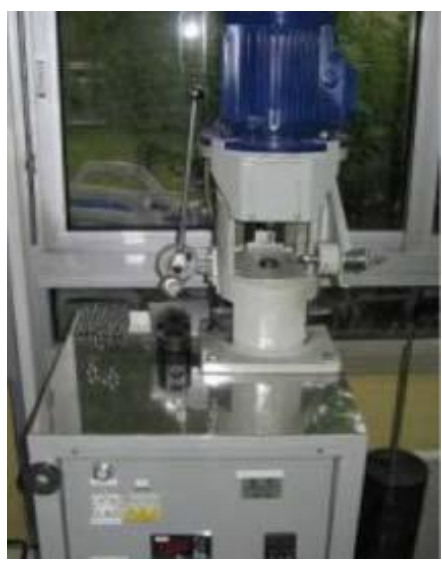

Fig.2. Four Balls Testing Machine

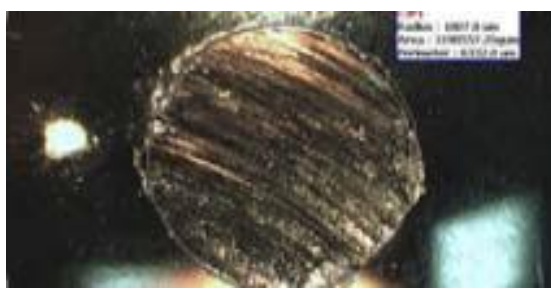

Fig.4. Example of Wear Scar on a Ball

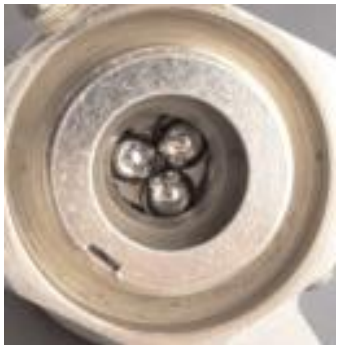

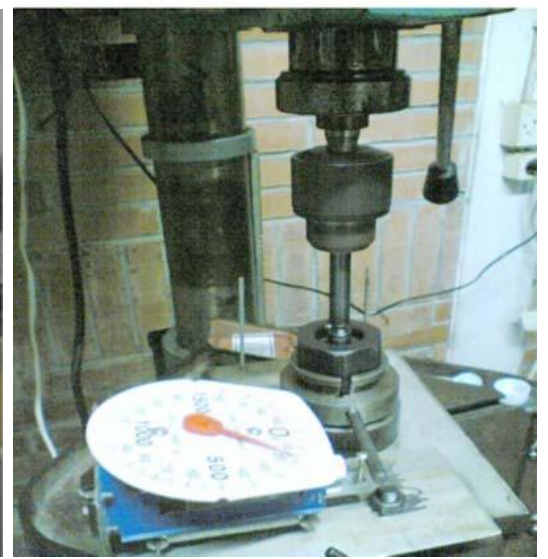

Fig.3. Modified Four ball tester

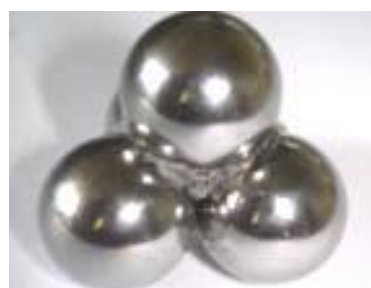

Fig.5. Four Welded Balls after Test
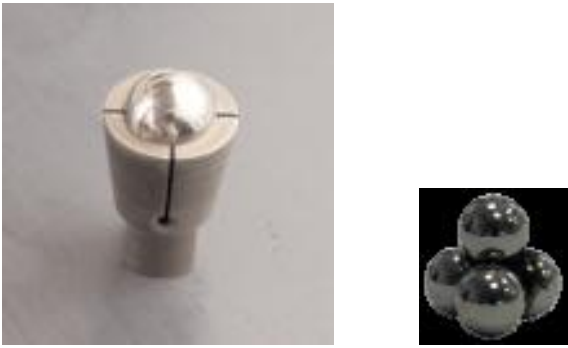

Fig.6. Example of Welded Test Balls

XI. EXPERIMENTAL WORK

The following different types of lubricating oils (i.e.SAE20, SAE90, SAE140) tested by the Four Ball Extreme Pressure Oil Testing Machine without And with E.P. Additives added in to the oils, these oils evaluated and investigated, and tabulated in the following tables.

\section{THE FOLLOWING ABBREVIATIONS USED}

(1) LNSR/L-Last Non Seizure Region/Load

(2) ISR/L-Initial Seizure Region/Load

(3) IMSR/L-Immediate Seizure Region/Load

(4) JBWR/L-Just Before Weld Region/Load

(5) WR/L-Weld Region/Load

TABLE:-2 OIL-SAE20

\begin{tabular}{|c|c|c|c|c|c|c|}
\hline $\begin{array}{l}\text { SR. } \\
\text { NO. }\end{array}$ & $\begin{array}{c}\text { PRESSURE } \\
\text { (P) } \\
\text { KG/CM } \\
\end{array}$ & $\begin{array}{l}\text { APPLIED } \\
\text { LOAD } \\
\text { (W) KG }\end{array}$ & $\begin{array}{c}\text { TEMPERAT } \\
\text { URE } \\
\text { (T) }{ }^{0} \mathrm{C}\end{array}$ & $\begin{array}{l}\text { TIME } \\
\text { (T) } \\
\text { SEC. }\end{array}$ & $\begin{array}{l}\text { MINIMUM } \\
\text { SCAR } \\
\text { DIAMETER } \\
\text { (D) MM }\end{array}$ & $\begin{array}{c}\text { REMARKS } \\
\text { REGIONS } \\
/ \\
\text { LOADS }\end{array}$ \\
\hline 1 & 5 & 25 & 25 & 10 & 0.4440 & LNSR/L \\
\hline 2 & 10 & 50 & 27 & 10 & 0.5750 & ISR/L \\
\hline 3 & 15 & 75 & 29 & 10 & 0.6320 & ISR/L \\
\hline 4 & 20 & 100 & 31 & 10 & 0.6505 & ISR/L \\
\hline 5 & 25 & 125 & 33 & 10 & 0.6760 & ISR/L \\
\hline 6 & 30 & 150 & 35 & 10 & 0.8660 & IMSR/L \\
\hline
\end{tabular}


Experimental Analysis Of Tribological Properties Of Various Lubricating Oils Without And With

\begin{tabular}{|c|c|c|c|c|c|c|}
\hline 7 & 35 & 175 & 37 & 10 & $\mathbf{0 . 8 6 8 5}$ & IMSR/L \\
\hline 8 & 40 & 200 & 39 & 10 & 0.9010 & IMSR/L \\
\hline 9 & 45 & 225 & 41 & 10 & $\mathbf{0 . 9 7 9 0}$ & IMSR/L \\
\hline 10 & $\mathbf{5 0}$ & $\mathbf{2 5 0}$ & $\mathbf{4 3}$ & $\mathbf{1 0}$ & $\mathbf{0 . 9 7 9 5}$ & IMSR/L \\
\hline 11 & $\mathbf{5 5}$ & $\mathbf{2 7 5}$ & $\mathbf{4 5}$ & $\mathbf{1 0}$ & $\mathbf{1 . 0 7 0 5}$ & IMSR/L \\
\hline 12 & $\mathbf{6 0}$ & $\mathbf{3 0 0}$ & $\mathbf{4 7}$ & $\mathbf{1 0}$ & $\mathbf{1 . 0 9 1 5}$ & IMSR/L \\
\hline 13 & $\mathbf{6 5}$ & $\mathbf{3 2 5}$ & $\mathbf{4 9}$ & $\mathbf{1 0}$ & $\mathbf{1 . 2 2 5 5}$ & IMSR/L \\
\hline 14 & $\mathbf{7 0}$ & $\mathbf{3 5 0}$ & $\mathbf{5 1}$ & $\mathbf{1 0}$ & $\mathbf{1 . 5 2 3 0}$ & IMSR/L \\
\hline 15 & $\mathbf{7 5}$ & $\mathbf{3 7 5}$ & $\mathbf{5 3}$ & $\mathbf{1 0}$ & $\mathbf{1 . 7 8 7 0}$ & JBWR/L \\
\hline 16 & $\mathbf{7 8}$ & $\mathbf{3 9 0}$ & $\mathbf{5 5}$ & $\mathbf{1 0}$ & $\mathbf{2 . 2 2 7 5}$ & WR/L \\
\hline
\end{tabular}

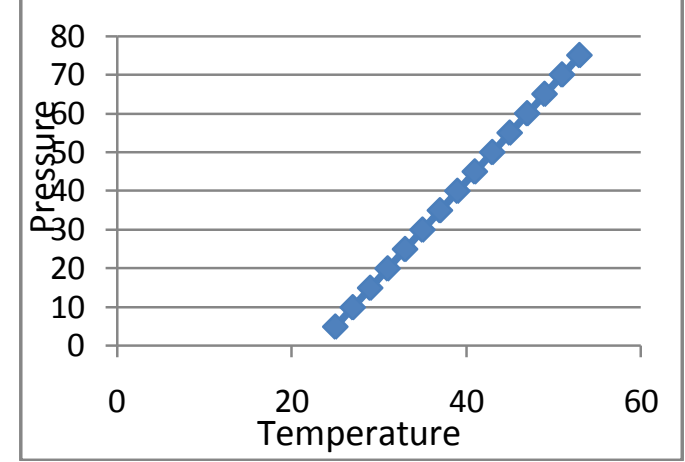

GRAPH .1. PRESSURE VS TEMPERATURE (FOR OIL SAE20)

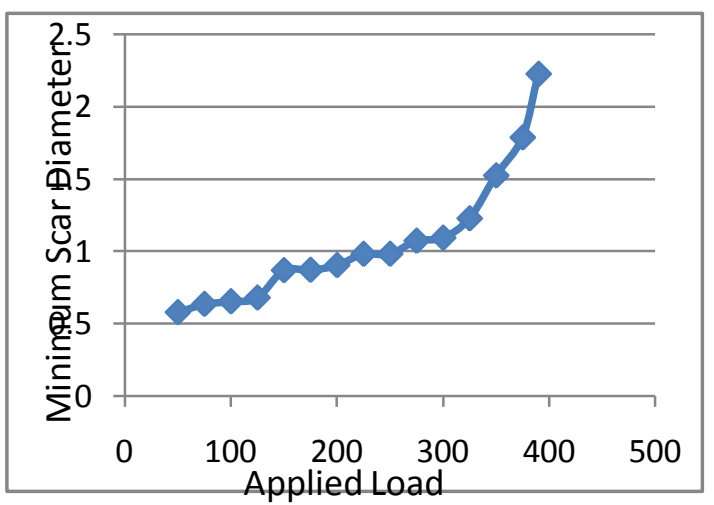

GRAPH .2. MINIMUM SCAR DIAMETER (D) MM VS APPLIED LOAD (W) KG(FOR OIL SAE20)

\begin{tabular}{|c|c|c|c|c|c|c|}
\hline $\begin{array}{l}\text { SR. } \\
\text { No. }\end{array}$ & $\begin{array}{c}\text { PRESSURE } \\
(\mathrm{P}) \\
\mathrm{KG} / \mathrm{CM}^{2}\end{array}$ & $\begin{array}{l}\text { APPLIED } \\
\text { LOAD } \\
\text { (W) KG }\end{array}$ & $\begin{array}{l}\text { TEMPERATURE } \\
\text { (T) }{ }^{\circ} \mathrm{C}\end{array}$ & $\begin{array}{l}\text { TIME } \\
\text { (T) SEC. }\end{array}$ & $\begin{array}{l}\text { MINIMUM } \\
\text { SCAR } \\
\text { DIAMETER } \\
\text { (D) MM } \\
\end{array}$ & $\begin{array}{c}\text { REMARKS } \\
\text { REGIONS } \\
/ \\
\text { LOADS } \\
\end{array}$ \\
\hline 1 & 20 & 100 & 35 & 10 & 0.9430 & LNSR/L \\
\hline 2 & 25 & 125 & 37 & 10 & 1.0560 & ISR/L \\
\hline 3 & 30 & 150 & 39 & 10 & 1.0920 & ISR/L \\
\hline 4 & 35 & 175 & 41 & 10 & 1.1915 & ISR/L \\
\hline 5 & 40 & 200 & 43 & 10 & 1.3055 & ISR/L \\
\hline 6 & 45 & 225 & 45 & 10 & 1.3500 & IMSR/L \\
\hline 7 & 50 & 250 & 47 & 10 & 1.4390 & IMSR/L \\
\hline 8 & 55 & 275 & 49 & 10 & 1.5560 & IMSR/L \\
\hline 9 & 60 & 300 & 53 & 10 & 1.5860 & IMSR/L \\
\hline 10 & 65 & 325 & 57 & 10 & 1.6465 & IMSR/L \\
\hline 11 & 70 & 350 & 60 & 10 & 1.8500 & IMSR/L \\
\hline 12 & 75 & 375 & 65 & 10 & 2.1630 & IMSR/L \\
\hline 13 & 80 & 400 & 69 & 10 & 2.4445 & IMSR/L \\
\hline 14 & 85 & 425 & 71 & 10 & 2.6055 & JBWR/L \\
\hline 15 & 90 & 450 & 73 & 10 & 2.6115 & WR/L \\
\hline
\end{tabular}




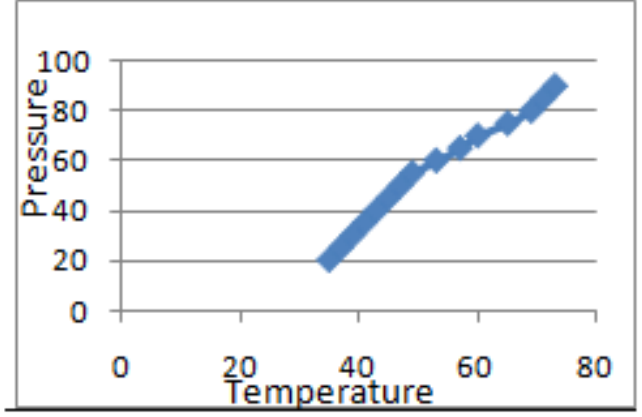

GRAPH 3. PRESSURE VS TEMPERATURE (FOR OIL SAE90)

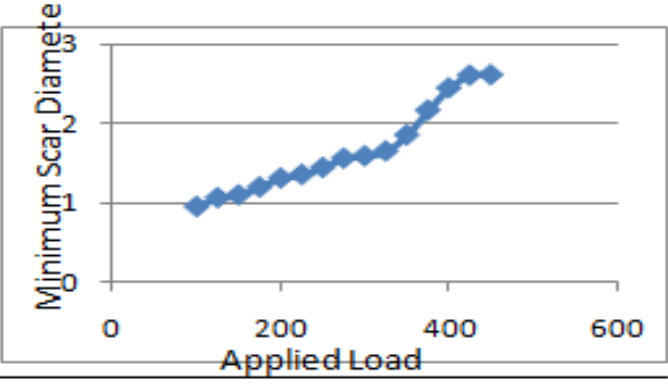

GRAPH 4. MINIMUM SCAR DIAMETER (D) MM VS APPLIED LOAD (W) KG (FOR OIL SAE90)

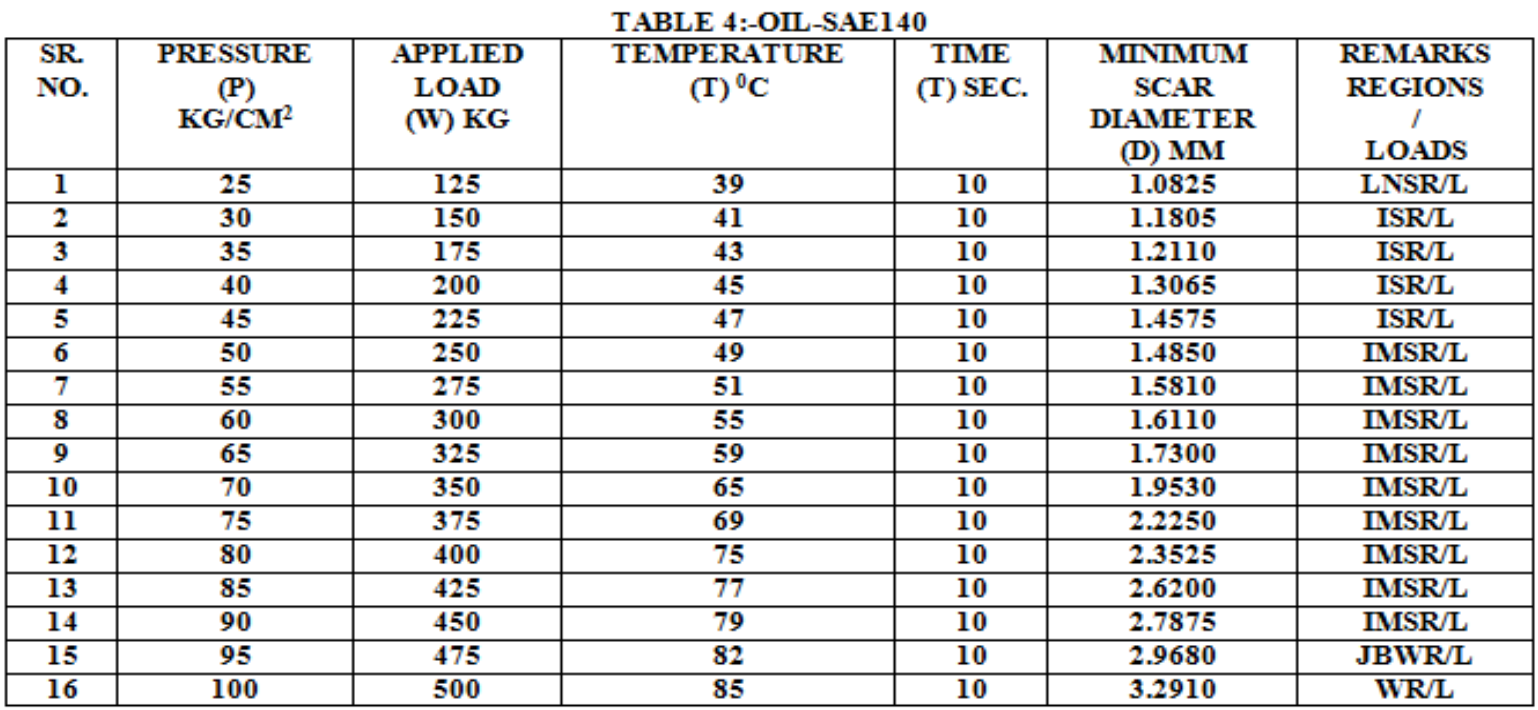

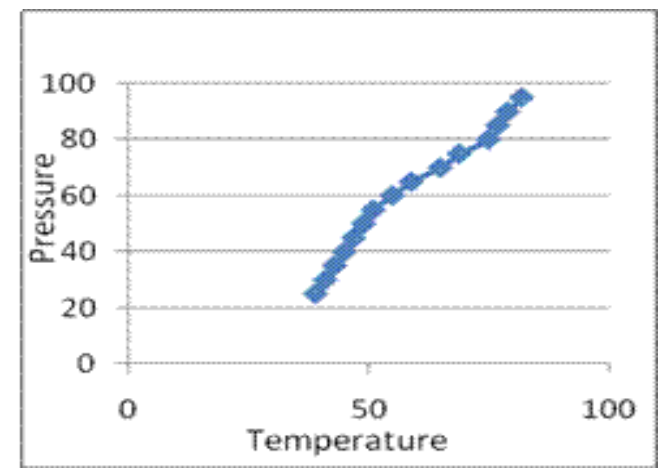

GRAPH 5. PRESSURE VS TEMPERATURE (FOR OIL SAE140)

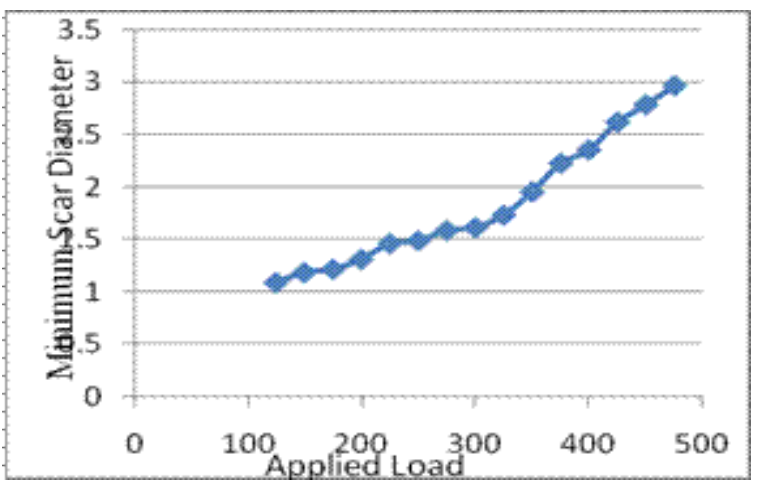


Experimental Analysis Of Tribological Properties Of Various Lubricating Oils Without And With

GRAPH 6. MINIMUM SCAR DIAMETER (D) MM VS APPLIED LOAD (W) KG (FOR OIL SAE140) TABLE 5:-SUMMARY OF TEST FOR WEAR SCAR DIAMETER IN MM FOR CHANGING LOAD

\begin{tabular}{|l|l|l|l|l|}
\hline \multicolumn{1}{|c|}{ Lubricants } & \multicolumn{1}{c|}{$\begin{array}{c}\text { Load } \\
\text { 60kg }\end{array}$} & \multicolumn{1}{c|}{$\begin{array}{c}\text { Load } \\
\mathbf{8 0 k g}\end{array}$} & $\begin{array}{c}\text { Load } \\
\mathbf{1 0 0 k g}\end{array}$ & \multicolumn{1}{c|}{$\begin{array}{c}\text { Load } \\
\mathbf{1 2 0 k g}\end{array}$} \\
\hline 140 Grade Oil & 1.2276 & 1.49125 & 1.832 & 2.032 \\
\hline 90 Grade Oil & 1.4546 & 1.676 & 1.984 & 2.184 \\
\hline 20W40 No. Oil. & 1.4596 & 1.84516 & 2.0343 & 2.2356 \\
\hline Break Oil & 2.401 & 3.3393 & 4.888 & 5.182 \\
\hline
\end{tabular}

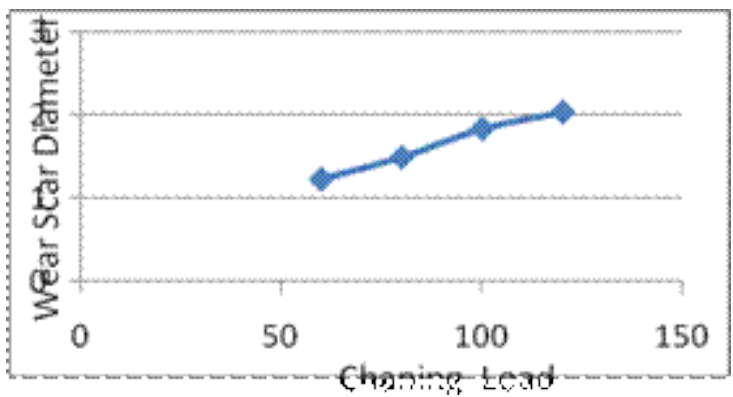

GRAPH 7. WEAR SCAR DIAMETER VS CHANGING LOAD (FOR 140 GRADE OIL)

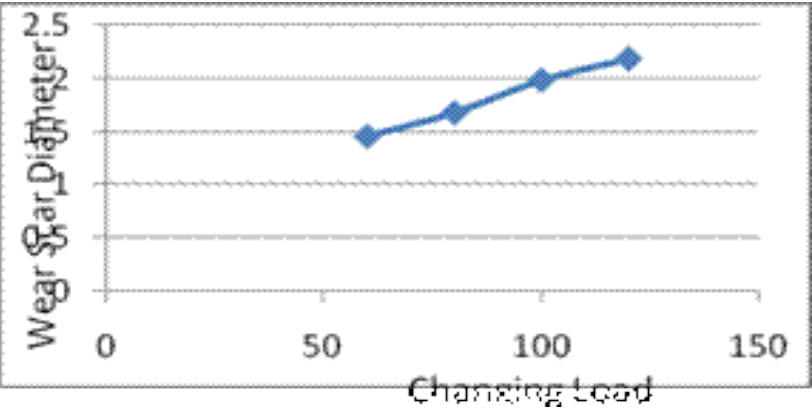

GRAPH 9. WEAR SCAR DIAMETER VS CHANGING LOAD (FOR 90 GRADE OIL)

TABLE 6.SUMMERY OF TEST FOR WEAR VOLUME IN MM ${ }^{3}$

\begin{tabular}{|c|c|c|c|c|}
\hline Lubricants & $\begin{array}{c}\text { Load } \\
\text { 60kg }\end{array}$ & $\begin{array}{c}\text { Load } \\
\mathbf{8 0 k g}\end{array}$ & $\begin{array}{c}\text { Load } \\
\text { 100kg }\end{array}$ & $\begin{array}{c}\text { Load } \\
\mathbf{1 2 0 k g}\end{array}$ \\
\hline 140 Grade Oil & 0.03337 & 0.07728 & 0.17728 & 0.25176 \\
\hline 90 Grade Oil & 0.06264 & 0.11623 & 0.22871 & 0.27865 \\
\hline 20W40 No. Oil & 0.06677 & 0.17093 & 0.25291 & 0.36947 \\
\hline Break Oil & 0.49227 & 1.86176 & 8.76619 & 11.1421 \\
\hline
\end{tabular}

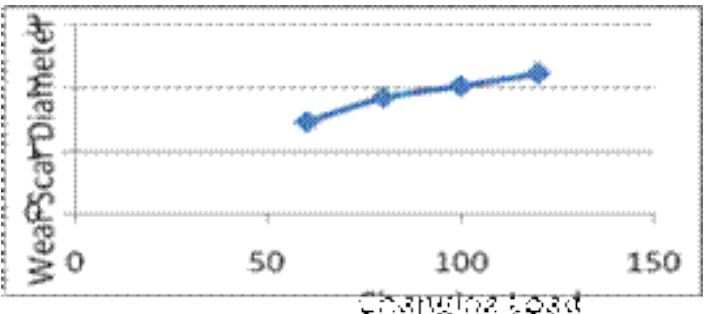

GRAPH 8. WEAR SCAR DIAMETER VS CHANGING LOAD (FOR 20W40 GRADE OIL)

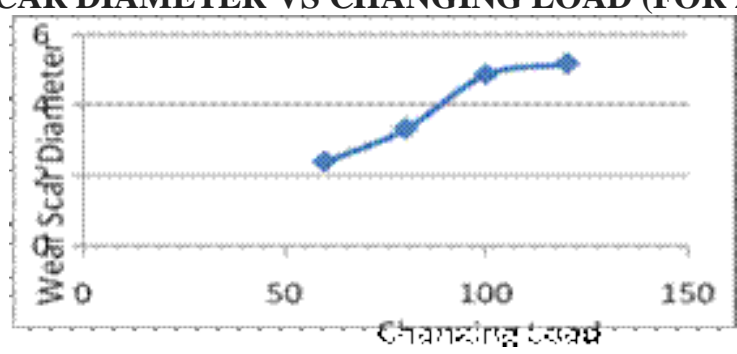

GRAPH 10. WEAR SCAR DIAMETER VS CHANGING LOAD (FOR BREAK OIL) 


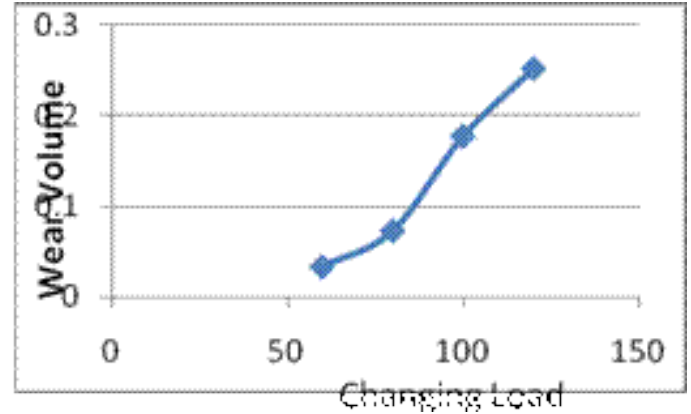

GRAPH 11. WEAR VOLUME VS CHANGING LOAD (FOR 140 GRADE OIL)

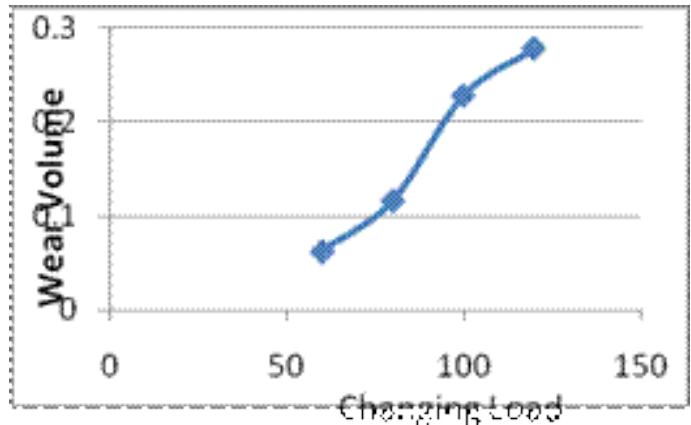

GRAPH 13. WEAR VOLUME VS CHANGING LOAD (FOR 90 GRADE OIL)

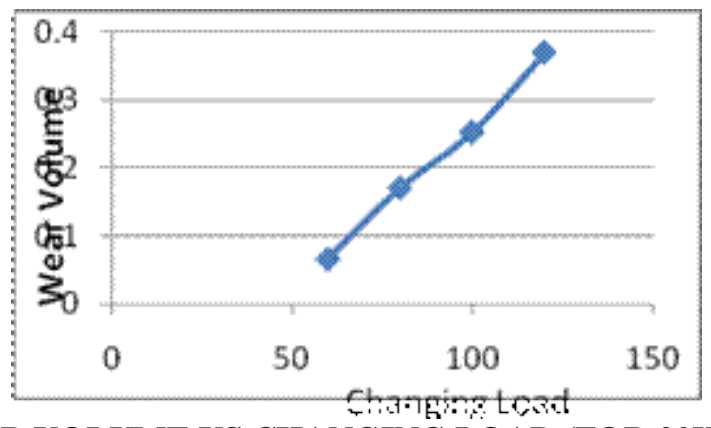

GRAPH 12. WEAR VOLUME VS CHANGING LOAD (FOR 20W40 GRADE OIL)

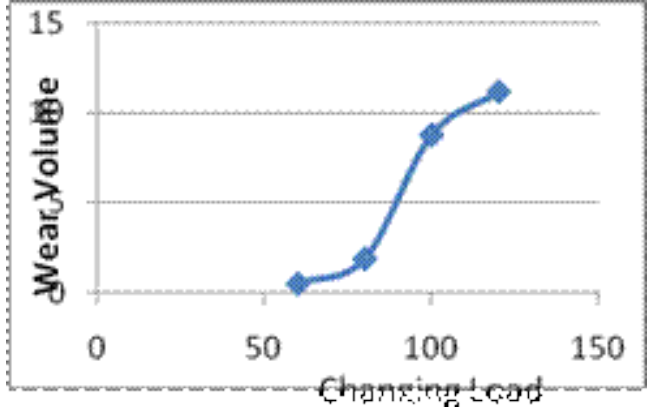

GRAPH 14. WEAR VOLUME VS CHANGING LOAD (FOR BREAK OIL)

XII.

CONCLUSION

The F.B.E.P.O.T.M. shows limited application in determining the EP activity of wear based oils for metal working processes. It is also observed (or finally concluded) that if Pressure or Applied Load increases the Minimum Scar Diameter, Weld Load and Temperature also increases.

It was demonstrated that there is in an almost direct proportionality between the mean scar diameter and the removed volumes of material from the fixed balls. The measurement of the mean scar diameter gives a good indication concerning the wear of the balls.

The Four Ball Extreme Pressure Oil Testing Machine which is used, for An Evaluation And Investigation Of Tribological Properties Of Various Lubricating Oils ( i.e. to Find out the Load Carrying Capacity, Weld 
Loads/Points, And Wear Preventive Properties of Various Lubricating Oils) Without Additives And With Additives gives following results. The 60 to 90 minutes of testing are enough to determine the values for the mean scar diameter and consequently the anti-wear properties of the tested hydraulic oils.

This test method can be an efficient way for screening the friction reducing ability, anti wear property and extreme-pressure property of different type of lubricants; it can distinguish the comprehensive property of lubricants with good repeatability. If friction coefficient is between 0.05_0.1, it is in boundary lubricating state. And it can reduce friction coefficient, decrease wear rate, increase load-carrying capacity and improve boundary lubricating effect, especially when friction improver, anti-wear and EP additive are well compounded, and get an ideal wear reduction and EP anti-wear performances.

The establishment of this test method is the unique one in domestic, and it will push the research of super lubricants goes forward.

The formula's mathematical form shows a marked influence of hardness on wear in the mixed lubrication range. The function is not monotonic, but it has an extremum. The figures show a marked increase in wear resistance with hardness, which is in agreement with the general assumptions made. One can notice, however, an optimum dependent on the relationship between hardness and excitations $(p \mathrm{H}$ and $v)$, as indicated by the regression function and the character of changes in contour lines $d=$ const. The investigations show that hardness definitely plays a role in the friction process.

By using Additives of Two types (i.e. Molyvan A \& Vanlube 73) with varying percentage of 1\%, $2 \%$ $\& 3 \%$ and the wear scar diameters of the oils 140 No., 90 No., 20 W40 \& Break oils are shown in the following table (See Table 8).

TABLE 7:-Summary Of All Oils Shows The Various Parameters Without Additives Adding In The Various Lubricating Oils Used Sae20-Sae140

\begin{tabular}{|c|c|c|c|c|c|c|c|c|}
\hline SR.NO. & $\begin{array}{c}\text { PARAMETERS } \\
\mathbf{1}\end{array}$ & $\begin{array}{c}\text { SAE } \\
\mathbf{2 0}\end{array}$ & $\begin{array}{c}\text { SAE } \\
\mathbf{3 0}\end{array}$ & $\begin{array}{c}\text { SAE } \\
\mathbf{4 0}\end{array}$ & $\begin{array}{c}\text { SAE } \\
\mathbf{6 8}\end{array}$ & $\begin{array}{c}\text { SAE } \\
\mathbf{9 0}\end{array}$ & $\begin{array}{c}\text { SAE } \\
\mathbf{1 2 0}\end{array}$ & $\begin{array}{c}\text { SAE } \\
\mathbf{1 4 0}\end{array}$ \\
\hline $\mathbf{2}$ & $\begin{array}{c}\text { PPPLIED LOAD (P) } \\
\left(\mathbf{K g} / \mathbf{c m}^{2} \text { ) }\right.\end{array}$ & 78 & 80 & 82 & 85 & 90 & 95 & 100 \\
$\mathbf{( K g )}$ & 390 & 400 & 410 & 425 & 450 & 475 & 500 \\
\hline $\mathbf{3}$ & $\begin{array}{c}\text { TEMPERATURE (T) } \\
\text { ()) }\end{array}$ & 55 & 56 & 65 & 67 & 73 & 80 & 85 \\
\hline $\mathbf{4}$ & TIME (t) (Sec.) & 10 & 10 & 10 & 10 & 10 & 10 & 10 \\
\hline $\mathbf{5}$ & $\begin{array}{c}\text { MINIMUM SCAR } \\
\text { DIAMETER (d) } \\
(\mathbf{m m})\end{array}$ & 2.2275 & 2.2325 & 2.2915 & 2.5875 & 2.6115 & 2.6950 & 3.2910 \\
\hline
\end{tabular}

As per the above table7, I concluded that if pressure and Applied load incereses the temperature and wear scar diameter is also incerases for the same time taken for the experiment conducted (time for each experiment is 10 Seconds) and the vicosity of each oil is also decreases.

Secondly By using Additives of Two types (i.e. Molyvan A \& Vanlube 73) with varying percentage of $1 \%, 2 \% \& 3 \%$ and the wear scar diameters of the oils 140 No., 90 No., $20 \mathrm{~W} 40 \&$ Break oils are shown in the following table (See Table 8.).

TABLE 8:-WEAR SCAR DIAMETERS WITHOUT AND WITH ADDITIVES USED IN OILS

\begin{tabular}{|c|c|c|c|c|c|c|c|c|}
\hline \multirow[t]{2}{*}{$\begin{array}{l}\text { SR. } \\
\text { No. }\end{array}$} & \multirow[t]{2}{*}{$\begin{array}{l}\text { OILS } \\
\text { USED }\end{array}$} & \multirow{2}{*}{$\begin{array}{l}\text { WEAR SCAR } \\
\text { DIAMETER } \\
\text { (MM) WITHOUT } \\
\text { ADDITIVES } \\
\text { USED } \\
\end{array}$} & \multicolumn{3}{|c|}{$\begin{array}{l}\text { WEAR SCAR DIAMETER } \\
\text { (MM) WITH ADDITIVES } \\
\text { USED PERCENTAGES }\end{array}$} & \multicolumn{3}{|c|}{$\begin{array}{l}\text { WEAR SCAR DIAMETER } \\
\text { (MM) WITH ADDITIVES } \\
\text { USED PERCENTAGES }\end{array}$} \\
\hline & & & \multicolumn{3}{|c|}{ MOLYVAN A } & \multicolumn{3}{|c|}{ VANLUBE 73} \\
\hline & & & $1 \%$ & $2 \%$ & $3 \%$ & $1 \%$ & $2 \%$ & $3 \%$ \\
\hline 1 & 140 NO. & 1.2276 & 1.1362 & 1.0173 & 1.3013 & 1.0692 & 0.9828 & 0.8157 \\
\hline 2 & $90 \mathrm{NO}$. & 1.4546 & 1.3117 & 1.1889 & 1.125 & 1.2646 & 1.1914 & 1.0894 \\
\hline 3 & $20 \mathrm{~W} 40$ & 4.4912 & 1.4015 & 1.3255 & 1.3013 & 1.3513 & 1.2895 & 1.2775 \\
\hline 4 & BREAK & 2.401 & 2.1558 & 1.9524 & 1.8478 & 2.0435 & 1.7818 & 1.5320 \\
\hline
\end{tabular}


(1) BOOKS

\section{BIBLIOGRAPHY}

[1] J.Halling, Principles of Tribology, 1981.

[2] Carleton N. Rowe, Lubricated Wear- Hand Book pf Lubrication (Theory and Practice Tribology), Vol.2, 209-223. (Copyright $\odot 1983$ CRC Press LLC).

[3] Donald H. Buckley, William R. Jones, Jr., Harold E. Sliney, Erwin V. Zaretsky, Dennis P. Townsend and Stuart H. Loewenthal (Lewis Research Center Cleveland, Ohio) NASA Technical Memorandum 101430, Tribology: The Story Of Lubrication and Wear, Prepared for Seminar F-107 at the 1985 International Trade Fair Cleveland, Ohio, October 18, 1985.

[4] Lubricating Oils, Greases, Specialty Lubricants, and Lubrication Systems- Lubrication Fundamentals (Naval Ships' Technical Manual Chapter 262 This Chapter Supersedes Chapter 262 Dated 1 June 1993 Distribution Statement C: Distribution Authorized To U.S. Government Agencies and Their Contractors; Administrative and Operational Use (31 January 1992). Other Requests For This Document Will Be Referred To the Naval Sea Systems Command (Sses622))

[5] M.F.Spotts, "Design of Machine Elements." Tata McGraw Hill Publication New Delhi. (1996)147-161, 184-187, 290-298, 423-440.

[6] Bharat Bhushan, Principles and Applications of Tribology, Powell, Ohio, June 1998, A Wiley-Inter science Publication John Wiley \& Sons, Inc. New York / Chichester / Weinheim / Brisbane / Singapore / Toronto (Ohio Eminent Scholar And the Howard D. Winbigler Professor Director, Computer Microtribology and contamination Laboratory Department of Mechanical Engineering the Ohio State University Columbus, Ohio)

[7] B.C.Mujumdar, introduction to tribology of bearing, 1999.

[8] AV. Pantar and P. Ghosh,"Effect of Viscosity modifiers on Viscometric and Wear Performance of lubricants, Industrial Tribology-Indian Institute of Petroleum Dehradun, India (March2002).

[9] Lawrence G. Ludwig, Jr. is chief chemist/technical director for Schaeffer Manufacturing in St. Louis, Missouri. Lubrizol Corporation. Industrial Lubricant Test Booklet, Noria Corporation. Best Practices for Machinery Lubrication Course Manual, Lubricant Properties and Tests. Machinery Lubrication (May2004), PP.10, 20, 25.

[10] PSG. Tech. Design Data Book Complied by Faculty of Mech. Engineers. PSG COE, Coimbatore-4) 1.25, 4.1 - 4.5, 7.21- 7.27, 7.58-7.70.

[11] HEINZ HEINEMANN (Founding Editor) Berkeley, California, JAMES G.SPEIGHT (Series Editor) University of Trinidad and Tobago O'Meara Campus, Trinidad Lubricant ADDITIVES CHEMISTRY AND APPLICATIONS, Second Edition CHEMICAL INDUSTRIES (A Series of Reference Books and Textbooks)

[12] Waldemar Tuszynski, Remigiusz Michalczewski, Witold Piekoszewski and Marian Szczerek (Institute for Sustainable Technologies - National Research Institute, ITeE-PIB, Poland) Modern Automotive Gear Oils - Classification, Characteristics, Market Analysis and Some Aspects of Lubrication. (New Trends and Developments in Automotive Industry).

[13] Ducom Company Manual (MFRS of Material Testing Equipment Banglore -560058, India.), 2.

(2) JOURNALS

[1] Block, H. (1963), "Inverse Problems in Hydrodynamic Lubrication and Design Directives for Lubricated Flexible Surfaces," Proceedings of the International Symposium on Lubrication and Wear, June 10-28, 1963, Houston, TX, (Eds. D. Muster and B. Sternlicht) McCutchan Berkeley, CA, pp 66.

[2] James J.O' Connor, John Boyd, Eugene A.A. Vallone, [Professor of Mechanical Engineering. The City College of New York] "Standard handbook of Lubrication Engineering". McGraw Hill Book CompanyNew York. [Sponsored by the American Society of Lubrication Engineering- ASLE). (1964) 20.19, 27.127.8

[3] Begelinger, A. and de Gee, A.W.J. (1972), "Boundary Lubrication of Sliding Concentrated Steel Contacts, Wear, 22, pp 337-357.

[4] Hamrock, B.J. and Dowson, D. (1981), Ball Bearing Lubrication, John Wiley and Sons: New York.

[5] Begelinger, A. and de Gee, A.W.J. (1982), "Failure of Thin Film Lubrication: A Detailed Study of the Lubricant Film Breakdown Mechanism," Wear, 77, pp 57-63.

[6] Yahagi, Y. and Mizutani, Y. (1984), "Corrosive Wear of Steel in Gasoline- Ethanol- Water Mixture," Wear, 97, pp 17-25.

[7] Yasutomi, S., Bair, S. and Winer, W.O. (1984), "An Application of a Free Volume Model to Lubricant Rheology 1-Dependence of Viscosity on Temperature and Pressure," Trans ASME, Journal of Tribology, 106, pp 291-303.

[8] Ohno, N., Kuwano, N. and Hirano, F. (1988), "Observation of Mechanical Behavior of Solidified Oils by Using Photoelastic Method,” Journal of Japan Society of Lubrication Engineers, 33, 9, pp 693-699. 
[9] Mori, S. and Morales, W. (1990), "Decomposition of Perfluoroalkylpolyethers (PFPE) in Ultra-High Vacuum Under Sliding Conditions," Tribol. Trans., 33, 3, pp325-332.

[10] Editor by Sudhir Singhal "Recent Advance in Tribology" papers presented at The Xth National conference on "Industrial Tribology" Indian Institute of Petroleum, Dehradun, India. March 24-26, 1993; Tata MC Graw Hill Publishing Company Ltd. New Delhi.

[11] 10.1.V.K. Jain, B.M. Shukla, and D.S. Shukla, "Tribological Indices Under different Modes of lubrication conditions for metal working".269- 274.

[12] 10.2. R.P.S. Bisht, M.R. Tayagi, P.C. Nautiyal and V.K. Bhatia. "Potential use of Jojoba Oil and its Derivatives as soluble cutting oil". 275- 279.

[13] 10.3.V.K.Varma, A.Bhattacharya, T.Singh, A. P. Singh and R. Singh (Center for Tribology, Deptt.Of Applied Chemistry, Institute of Technology, Banaras Hindu University,Varanasi) "A Tribological Study in Wear and Friction Reduction Using Certain N, S And O.Containing Hetrocyclic compounds as potential E.P. Additives". 345-347.

[14] 10.4. T.Singh and C.V. Chandrasekharan (Balmer Lawrie and Co. Ltd. Corporate R \& D, P.43, Hide Rd. Extn (Culcutta- 700088), New Additives for extreme Pressure Lubrication.351-355.1

[15] 10.5. B.C.Majumdar (Professor of Mech. Engg. Dept,) I.I.T.Kharagpur India, "Lubrication Theories"3.

[16] Jones, W.R., Jr., Pepper, S.V., Herrera-Fierro, P., Feuchter, D., Toddy, T.J., Jayne, D.T., Wheeler, D.R., Abel, P.B., Kingsbury, E., Morales, W., Jansen, R., Ebihara, B., Helmick, L.S., and Masuko, M. (1994), "The Preliminary Evaluation of Liquid Lubricants for Space Applications by Vacuum Tribometry," 28th Aerospace Mech. Symp, NASA Lewis Research Center, Cleveland, OH. N 94-33313.

[17] Sharma, S.K., Rosado, L., Ho" glund, E. and Hamrock, B.J. (1995), "Rheology of Perfluoropolyalkylether Fluids in Elastohydrodynamic Lubrication,” Tribol. Trans., 38, 4, pp 769-780.

[18] Jones, W. R., Jr. (1995), "Properties of Perfluoropolyethers for Space Application,"'Tribol. Trans., 38, 3, pp 557-564.

[19] H.H.Masjuki, M.A.Maleque,"Investigation of anti-wear characteristics of palm oil Methyl ester using a four ball tribometer test". (Elsevier) wear 206 (1997), pp 179-186.

[20] Richard E. Rush (Member, STLE, the Uno-ven Company, Arlington Hights, Illinois), "A review of the more common standard grease tests in use today." Journal of the Society of Tribologists \& Lubrication Engineers (JSTLE - Lubrication Engineering) Volume 54, No.3 (March 1997) 22, 24 to 25.16. S.P. Jones \& Ralph Jansen (Member, STLE) (Ohio Are space Institute Cleveland, Ohio- 44135) and Robert L. Fusaro (Fellow, STLE) (National Aeronautics and space Administration - NASA, Lewis research Center, Cleveland Ohio-44135), "Preliminary Investigation of Neural Network Techniques Predict Tribological Properties" Tribology transactions Volume-40, No.2. (April 1997) 314-316, 319.

[21] 17. Lubrication Engineering (Section-I, Fundamental, Concepts and Practices), Lubrications Foundations association of Iron and steel engineers (AISE). Volume 53, No.9 (Sept.1997)32.

[22] 18. Ohno, N., Sunahara, K., Kumamoto, T. and Hirano, F. (1999), "Prediction of Liquid Lubricant Viscosity at High Pressure From the Density Measurements," Journal of Japanese Society of Tribologists, 44, 7, pp 560-566.

[23] 19. Svajus Asadauskas, Joseph M. Perez and J. Larry Duda (Member STLE, The Pennsylvania State University, Dept. of chemical Engg. University) Park Pennsylvania16802). JSTLE, Lubrication Engineering Volume 53, No.12 (Dec.1997) 35-40.

[24] 20. Bruno Delfort, Agens Chive, Bertrand Daoudal and Thierry Lacome (Institute Francais Du petrole, 92506, Rueil-Malmasion Cedex, France "Phosphosulfuration of colloidal Calcium carbonate, Evaluation of Antiwear and Extreme - Pressure Properties" Tribology Transaction. Volume- 41, No.1 (Jan1998)142- 144.

[25] 21. Lois J. Gschwender (Member STLE), Shashi K. Sharma (Member STLE), Carl E. Snyder, Jr.(Fellow, STLE) [Wright Laboratory, WPAFB, Ohio - 45433- 7750. Larry Helmick (Cedarville College, Cedarville, Ohio-45314-0601).George W. Fultz and Bruce Schreiber (University of Dayton research Institute, Dayton, Ohio- 45469- 0168),"The effect of Additives on the wear behavior of Bearing Steels with R fO (CF2O)x (CF2CF2O)y (CF2CF2O) z Rf Perfluoropolyalkyletherfluids". Tribology Transactions, Volume 41, No.1 (April

[26] 1998) 78-86.

[27] 22. William R. Jones, Jr. Agnieszka K. Poslowsk,' Bradley A Shogrin, Pillar Herrera- Fierro and Mark J. Jansen.(Cleveland, University heights, Brook Park- Ohio); "Evaluation of Several Space Lubricants using a Vacuum four Ball Tribometer",. ASME/ STLE - Tribology Transactions Volume-42, No.2 (1999)319. \& NASA/TM- 1998-208654.

[28] 23. Sukirno (University of Indonesia, Depok- 16424, Indonesia) Masabnmi Masuko (M.STLE) Tokyo Inst. of Technology, Tokyo-152- 8552, Japan)“Oxidative Degradation Of Mineral Oil under Tribocontact and Ineffectiveness of Inhibitors". Volume 42, (1999), 324-330. 
[29] 24. H.Li (Midland, Michigan 48642), K.K. Chao (Dayton, Ohio- 45469-0166), J.L.Duda And E.E. Kluns (University Park, Pennsylvania 16802) "A study of wear chemistry and Contact temperature using a Micro sample Four-Ball wear Test". Tribology Transaction. Volume 42, No.3 (1999)529-530-534.

[30] 25. Perez J. D. Weller, Jr. and J. Duda (1999) "Sequential Four-Ball Study of Some Lubricating Oils," Lubrication Engineering, September, pp 28-3, Practicing Oil Analysis (11/1999)

[31] Gschwender, L.J., Snyder, C.E., Jr., Massey, M. and Peterangelo, S. (2000), "Improved Liquid/Grease Lubricants for Space Mechanisms," Lubrication Engineering, 56, 12, pp 25-31.

[32] Rakesh Sehgal, O.P.Gandhi, S.angra "Wear Evaluation and ranking of Tribomaterials Using Hasse diagram approach, Transactions of the ASME, Volume 123,(2001), 486-493.

[33] Ohno, N. and Hirano, F. (2001), "High Pressure Rheology Analysis of Traction Oils Based on Free Volume Measurements," Lubrication Engineering, 57, 7, 16-22.

[34] Bair, S. (2001), "The Pressure-Viscosity Coefficient of a Perfluorinated Polyether Over a Wide Temperature Range," Trans ASME, Journal of Tribology, 123, pp 50-53.

[35] CAI Jiyuan, Gan Quan \&DAI Lixia,"Investigation on tribology behavior of lubricants Using the coefficient of friction test method" Science in China (Series A) (August 2001), Vol. 44. Supp., pp199206.

[36] Douglas Godfrey, Willam R. Hergruth, "Physical and Chemical Properties of Mineral Oils that affect lubrication "Research Paper in Hergruth Laboratories, (2002).

[37] Bair, S., Vergne, P. and Marchetti, M. (2002), "The Effect of Shear-Thinning on Film Thickness for Space Lubricants," Tribol. Trans., 45, 2, pp 330-333.

[38] N'Elias, D., Legrand, E., Vergne, P. and Momdier, J.-B. (2002), "Traction Behavior Of Some Lubricants Used for Rolling Bearings in Spacecraft Applications: Experiments and Thermal Model Based on Primary Laboratory Data," Trans ASME, Journal of Tribology, 124, pp 72-81.

[39] Ohno, N., Tanaka, T. and Komiya, H. (2005), "Anti-Wear Action by Solidified Oil Film in Sliding Concentrated Steel Contacts," Proc. of 1st International Conference on Manufacturing, Machine Design and Tribology, June 23-24, 2005, Seoul, South Korea, EFE-404, pp 1-4.

[40] Ohno, N., Rahman, M.Z. and Kakuda, K. (2005), "Bulk Modulus of Lubricating Oils as Predominant Factor Affecting Tractional Behavior in High-Pressure Elastohydrodynamic Contacts,” Tribol. Trans., 48, pp 165-170.

[41] Jian-Qiang Hu Li-Ming Hu, Jun-Bing Yaol (Department of Aviation Oil, Xu Zhou Air Force College, Xuzhou 221000 China, 1 Beijing Aviation Oil Research Institute, Beijing 100076, China ISSN 13377027 Available online at (www.vurup.sk/pc ) (Petroleum \& Coal 48 (2), 37-42, 2006), Evaluation On Synergistic Antiwear Properties Of Organic Antimony Compounds As Lubricant Additive

[42] Mia, S., Komiya, H., Hayashi, S. Morita, S. Ohno, N. andObara, S. (2007), "Viscosity Loss in PFPE Lubricant for Space Applications under EHL Conditions," Tribology Online, 2, 2, pp 54-58.

[43] Ohno, N. (2007), "EHL Behavior of Liquid Lubricants for Space Application," Journal Of Japan Society for Design Engineering, 42, 1, pp 9-14.

[44] Constantin SPANU, Minodora RIPA, Ioan Stefanescu, Lorena Deleanu "A Comparation of standardized Methods for Lubrication Failure Determination" The Annals of University Dunareab De Jos of Galati (Romania) Fascicle VIII, 2007 (XIII), ISSN 1221- 4590, Tribology.pp99-103.

[45] Oswald, F.B., Jett, T.R., Predmore, R.E. and Zaretsky, E.V. (2008), "Probabilistic Analysis of Space Shuttle Body Flap Actuator Ball Bearings,” Tribol. Trans., 51, 2, pp 193-203.

[46] YuHe-long, Xu Yi, Shi Pei-jing, Xu Bin-shi, Wang Xiao-li, Liu Qian, "Tribological Properties and lubricating mechanisms of $\mathrm{Cu}$ nanoparticles in lubricant."'Transactions of Nonefeerous Metals Socitey of China 18 (2008) 636- 641.

[47] Constantin SPANU, Minodora RIPA, Sorin Ciortan "Study of Wear Evaluation for Hydraulic oil using a Four Ball Tester" The Annals of University Dunareab De Jos of Galati (Romania) Fascicle VIII, 2008 (XIV), ISSN 1221- 4590, Tribology.pp186-189.

[48] Ohno, N., Komiya, H., Morita, S., Mia, S., Satoh, N. and Obara, S. (2009), "Bearing Fatigue Life Tests in Advanced Base Oil and Grease for Space Application,” Tribol. Trans., 52, 1, pp 114-120.

[49] Faiz Ullah Shah (Division of Chemical Engineering \& Division of Machine Elements Lulea University of Technology, SE- 97187 Luleå, SWEDEN) Boron Compounds as Additives to Lubricants: Synthesis, Characterization and Tribological Optimization (November 2009, Printed by Universitetstryckeriet, Lulea 2009, ISSN: 1402-1757, ISBN 978-91-7439-027-8, Luleå, www.ltu.se).

[50] Nobuyoshi Ohno, Sobahan Mia,Shigeki Morita And Shingo Obara(2010), "Friction and Wear Characteristics of Advenced Space Lubricants", (STEL), Tribology Transactions,53,249-255,

[51] Sukirno,Ludi,Rizqon,Bismo,Naskin(2010), "Anti-Wear Properties of bio-grease From modified palm oil and calcium soap thickener”.Agric Eng Inst: CIGR Journal,Vol.12,No.2.pp64-69. 
[52] M.Farooq, A.Ramli,S.Gul and N.Muhammad (2011),"The study of wear behavior Of 12-hydroxystearic Acid in vegetable oils"Journal of Applied Science 11(8):1381-1385.

[53] Plint Tribology Products from Phoenix tribology Ltd.(TE 92D Four Ball Test Machine with Dead Weight Loading)

[54] Tribologic-Evaluation of fluid properties using the 4-Ball Machine. Tribologic Ltd.C/O.School of Mechanical Engineering the University of Leeds LS2 9JT UK.

[55] Dr. B.S. Kothavale (Professor, Mechanical Department, MIT COE; Pune MS INDIA), Evaluation of Extreme Pressure Properties Lubricating Oils Using Four Ball Friction Testing Machine. (International Journal of Advanced Engineering Technology E-ISSN 0976-3945) (IJATE/Vol.II/IssueIII/JulySept.2011/56-58)

[56] Prof.A.D.Dongare \& Prof.Dr.G.J.Vikhe, The Standard Test Method For Measurement Of Extreme Pressure Properties Of Various Lubricating Oils By Using Four Ball Extreme Pressure Oil Testing Machine. International Journal of Engineering Research And Development-PEER REVIEVED JOURNAL)(Volume 4, Issue 6, e-ISSN: 2278-067X, p-ISSN: 2278-800X).(PP 6-11.)

[57] Prof.A.D.Dongare An Evaluation And Investigation Of Tribological Properties Of Various Lubricating Oils Without Using Extreme Pressure Additives By Using Four Ball Extreme Pressure Oil Testing Machine. International Journal Of Contemporary Research In Business Management, Engineering And Health Sciences. Bearing ISSN No.2320-1185, Vol.No.001, Issue No.001, Organizing International Conference On "What Moves The Growth? Challenges And Opportunities in Business Management and Engineering".15th \&16th Feb.2013, Sahyadri Institute of Pune.(PP141-146.)

[58] Prof.A.D.Dongare An Evaluation And Investigation Of Tribological Properties Of Various Lubricating Oils With Using Extreme Pressure Additives By Using Four Ball Extreme Pressure Oil Testing Machine. International Journal Of Contemporary Research In Business Management, Engineering And Health Sciences. Bearing ISSN No.2320-1185, Vol.No.001, Issue No.001, Organizing International Conference On "What Moves The Growth? Challenges And Opportunities in Business Management and Engineering".15th \&16th Feb.2013, Sahyadri Institute of Pune.(PP246-255).।

(3) AN ARTICLE PUBLISHED IN A CONFERENCE/SEMINAR PROCEEDINGS

[1] Raje N.R. \& Gupta R.K. (Indian Oil Corporation Ltd. Faridabad, Haryana) Tribological Considerations and Mechanical Testing of Industrial Lubricants, Published in First National Conference in Industrial Tribology, at Madras on Dec.18-21, 1974. PP. 61-68.

[2] Donald H. Buckley, William R. Jones, Jr., Harold E. Sliney, Erwin V. Zaretsky, Dennis P. Townsend and Stuart H. Loewenthal Lewis Research Center Cleveland, Ohio NASA Technical Memorandum 101430, Tribology: The Story of Lubrication And Wear, Prepared for Seminar F-107 at the 1985 International Trade Fair Cleveland, Ohio, October 18, 1985

[3] Mark Barnes, N Oria Corporation deploying ASTM performance tests in response To used oil analysis exceptions, practicing oil analysis 2001 conference Proceedings

\section{(4) WEB SITES}

[1] Http://www.machinery lubrication.com

[2] www.subtech.com (Additives in Lubrication)

[3] www.wikipedia.org/wiki/Extreme Pressure additive

[4] http://blog.sfrcorp.com/2007/06/21/extreme-pressure-agents-in-oil-additives

[5] www.falex.com www.falexint.com,

[6] Email: falexcorp@aol.com Email office@falexint.com)

[7] www.ducom.com ! Email: info@ducom.com,

[8] www.itee.radom.pl, www. tribologia.org, trib-dep@itee.radom.pl

[9] www.westpenn.com

[10] www.answers.com/topic/grease-lubricant http://www.normas.com/ASTM/Contants.

[12] 11. www.compass- falex instruments.com

[13] 12. www.koehlerinstrument.com 